\title{
Performance of a quantitative fecal immunochemical test for detecting advanced colorectal neoplasia: a prospective cohort study
}

Elizabeth G. Liles ${ }^{1 *}$ D, Nancy Perrin², Ana G. Rosales ${ }^{1}$, David H. Smith¹, Adrianne C. Feldstein ${ }^{1}$, David M. Mosen ${ }^{1}$ and Theodore R. Levin ${ }^{3}$

\begin{abstract}
Background: The fecal immunochemical test (FIT) is easier to use and more sensitive than the guaiac fecal occult blood test, but it is unclear how to optimize FIT performance. We compared the sensitivity and specificity for detecting advanced colorectal neoplasia between single-sample (1-FIT) and two-sample (2-FIT) FIT protocols at a range of hemoglobin concentration cutoffs for a positive test.

Methods: We recruited 2,761 average-risk men and women ages 49-75 referred for colonoscopy within a large nonprofit, group-model health maintenance organization (HMO), and asked them to complete two separate singlesample FITs. We generated receiver-operating characteristic (ROC) curves to compare sensitivity and specificity estimates for 1-FIT and 2-FIT protocols among those who completed both FIT kits and colonoscopy. We similarly compared sensitivity and specificity between hemoglobin concentration cutoffs for a single-sample FIT.

Results: Differences in sensitivity and specificity between the 1-FIT and 2-FIT protocols were not statistically significant at any of the pre-specified hemoglobin concentration cutoffs $(10,15,20,25$, and $30 \mu \mathrm{g} / \mathrm{g})$. There was a significant difference in test performance of the one-sample FIT between $50 \mathrm{ng} / \mathrm{ml}(10 \mu \mathrm{g} / \mathrm{g})$ and each of the higher pre-specified cutoffs. Disease prevalence was low.

Conclusions: A two-sample FIT is not superior to a one-sample FIT in detection of advanced adenomas; the onesample FIT at a hemoglobin concentration cutoff of $50 \mathrm{ng} / \mathrm{ml}(10 \mu \mathrm{g} / \mathrm{g})$ is significantly more sensitive for advanced adenomas than at higher cutoffs. These findings apply to a population of younger, average-risk patients in a U.S. integrated care system with high rates of prior screening.
\end{abstract}

Keywords: Colorectal neoplasms, Mass screening, Occult blood, Sensitivity and specificity

\section{Background}

Colorectal cancer (CRC) is the third-leading cause of cancer-related deaths in the United States, affecting men and women almost equally [1]. Population screening for CRC has reduced disease-related mortality due to high prevalence of resectable precancerous lesions that have a slow progression to clinically invasive cancer [2-6]. The fecal immunochemical test (FIT) has higher patient

\footnotetext{
* Correspondence: Beth.G.Liles@kpchr.org; Elizabeth.G.Liles@kp.org ${ }^{1}$ Kaiser Permanente Center for Health Research, 3800 N Interstate Ave, Portland, OR 97227, USA

Full list of author information is available at the end of the article
}

adherence [7-10] and better sensitivity than guaiac fecal occult blood testing (gFOBT) [11], leading to recommendations for its use in colorectal cancer screening [12-14]. Important questions about the optimal use of this test remain. In particular, it is unclear whether one or two samples should be collected and what hemoglobin cutoff for a positive test would optimize sensitivity and specificity for detection of cancers and advanced adenomas $[15,16]$. Organized CRC programs in different parts of the world use fecal tests requiring 1 , 2 or 3 fecal samples worldwide, without consensus about the optimal approach [17]. Theoretically, an extra fecal

(c) The Author(s). 2018 Open Access This article is distributed under the terms of the Creative Commons Attribution 4.0 International License (http://creativecommons.org/licenses/by/4.0/), which permits unrestricted use, distribution, and reproduction in any medium, provided you give appropriate credit to the original author(s) and the source, provide a link to the Creative Commons license, and indicate if changes were made. The Creative Commons Public Domain Dedication waiver (http://creativecommons.org/publicdomain/zero/1.0/) applies to the data made available in this article, unless otherwise stated. 
sample may provide the chance to detect an intermittently bleeding, clinically significant neoplasm. However, only a paucity of observational evidence, and no randomized trials address this question.

There are several different types of FIT available $[12,15]$. Large trials comparing the effectiveness of colonoscopy with FIT use the OC-Auto-FIT (prior names: OC Micro, OC Sensor) [18, 19], a quantitative FIT with results processed by an automated analyzer. This FIT has been found to be $80 \%$ sensitive for cancer when used at the manufacturer-recommended hemoglobin concentration cutoff of $100 \mathrm{ng} / \mathrm{ml}$ of buffer, or $20 \mu \mathrm{g} / \mathrm{g}$ of stool $[19,20]$. The sensitivity of the OC-Auto FIT can be increased further by lowering the cutoff of hemoglobin concentration for a positive test result [15], although it has been unknown what the trade-off in false positives would be at a lower cutoff if used in an average-risk screening population.

In the Maximizing Yield of the Fecal Immunochemical Test for Colorectal Cancer Screening (MY-FIT) study, we sought to determine the optimal combination of hemoglobin concentration cutoff and fecal samples for the OC-Auto FIT by evaluating FIT performance among patients completing screening colonoscopy. We conducted our study among members of a nonprofit, groupmodel health maintenance organization (HMO) who were ages 50-75, at average risk for CRC, and due for CRC screening.

\section{Methods}

\section{Summary}

For this cohort study, we recruited patients referred for screening colonoscopy and requested that they complete two separate single-sample FITs labeled " 1 " and "2," from two separate bowel movements. We then compared sensitivity and specificity estimates for 1-FIT and 2-FIT protocols among those who completed both FIT samples and the colonoscopy. Trained study staff analyzed the concentration of hemoglobin $(\mathrm{ng} / \mathrm{ml})$ for each FIT sample. Analysis occurred before colonoscopy completion; therefore, study staff was blind to colonoscopy results. We compared sensitivity and specificity estimates according to a range of hemoglobin concentration cutoffs for a positive test [21]:

- $50 \mathrm{ng} / \mathrm{ml}(10 \mu \mathrm{g} / \mathrm{g})$

- $75 \mathrm{ng} / \mathrm{ml}(15 \mu \mathrm{g} / \mathrm{g})$

- $100 \mathrm{ng} / \mathrm{ml}(20 \mu \mathrm{g} / \mathrm{g})$

- $125 \mathrm{ng} / \mathrm{ml}(25 \mu \mathrm{g} / \mathrm{g})$

- $150 \mathrm{ng} / \mathrm{ml}(30 \mu \mathrm{g} / \mathrm{g})$

\section{Study site}

Kaiser Permanente Northwest (KPNW) is a nonprofit, group-model HMO with about 542,000 members in
Southwest Washington and Northwest Oregon. It owns and operates two hospitals, contracts with six other local hospitals, and maintains 22 medical clinics (17 with primary care). Northwest Permanente, the medical provider group that serves KPNW patients, includes 797 physician members and 395 allied clinicians; of these, 265 are primary care providers. KPNW has a stable membership that is similar to the local insured community in terms of age, gender, race, and ethnicity. About $86 \%$ of members are white, about $7 \%$ are ethnically Hispanic, $6 \%$ are Asian, and $4 \%$ are African American. Membership turnover in the 50-plus age group averages $8.5 \%$ per year. Since 1996, KPNW has maintained complete electronic medical records (EMRs) for each health plan member, and its administrative and clinical databases are available for research purposes; members provide consent to use their data for research purposes upon enrollment or can opt out.

In $2009 \mathrm{KPNW}$ updated its clinical-practice guideline pertaining to CRC screening. This guideline is based on recommendations of the US Preventive Services Task Force, which state that persons aged 50 to 75 and at average risk should be offered CRC screening. All of the United States Preventive Services Task Force (USPSTF)-recommended CRC-screening modalities are covered services.

\section{Subjects}

We identified men and women aged 49-75 who received a referral for screening colonoscopy between December 1, 2011, and June 30, 2014, using the EMR. For each consecutive referred individual, we used three methods to apply exclusion criteria: 1) automated extraction from the medical record using diagnosis and referral codes, 2) chart review (of those with iron-deficiency anemia, to confirm no apparent known cause) and 3) detailed telephone interview to further screen and to determine interest. Table 1 lists the exclusion criteria. We excluded patients with dementia, end-stage renal disease, or HIV/AIDS to align the population with that of a randomized trial that utilized screening outreach exclusion criteria [22]. We developed symptom and anemia criteria by considering referral guidelines for suspected lower gastrointestinal cancer [23], as well as existing literature [24-26].

\section{Study materials}

We mailed two FIT kits (OC-Auto FIT; Polymedco, Inc., Cortland Manor, NY) and instructions to participants who consented to be part of the study. No dietary or medication restrictions were advised. Participants were asked to label each sample with a date, and to collect the sample marked " 1 " on an earlier date, and sample "2" on a later date. Participants could use the enclosed 
Table 1 Exclusion criteria for the study population

\begin{tabular}{|c|c|c|}
\hline & Category of exclusion & Exclusion criteria \\
\hline \multirow[t]{16}{*}{ High risk diagnosis } & \multirow[t]{2}{*}{ History of cancer in the colon or rectum } & Personal history of colorectal cancer \\
\hline & & Personal history of carcinoid of the colon \\
\hline & \multirow[t]{2}{*}{ Inflammatory bowel disease } & Crohn's disease \\
\hline & & Ulcerative colitis \\
\hline & \multirow[t]{7}{*}{ Inherited colorectal cancer syndrome } & Familial adenomatous polyposis \\
\hline & & Peutz-Jegher's syndrome \\
\hline & & Gardner syndrome \\
\hline & & Lynch syndrome \\
\hline & & Cowden syndrome \\
\hline & & Juvenile polyposis \\
\hline & & MYH-associated polyposis \\
\hline & \multirow[t]{2}{*}{ Unexplained iron-deficiency anemia } & $\begin{array}{l}\text { Men with a hemoglobin }<11 \text {, and women with a hemoglobin } \\
<10 \text {, in combination with a ferritin of less than } 100\end{array}$ \\
\hline & & No reasonable explanation (e.g., recent surgery) for the anemia \\
\hline & Recent weight loss & $\geq 10 \%$ of body weight or $\geq 20 \mathrm{lbs}$. in the prior 6 months \\
\hline & $\begin{array}{l}\text { A combination of age and lower gastrointestinal } \\
\text { symptoms suggestive of colorectal cancer }\end{array}$ & $\begin{array}{l}\text { Age greater than } 60 \text { years, plus rectal bleeding for } \geq 3 \text { months, and } \\
\text { change in bowel habits toward looser stools or increased stool frequency } \\
\text { persisting for six weeks or more }\end{array}$ \\
\hline & History of adenomas & Prior history of adenomatous polyps \\
\hline \multirow{2}{*}{\multicolumn{2}{|c|}{ Recent endoscopy }} & Colonoscopy within 10 years \\
\hline & & Flexible sigmoidoscopy within 5 years \\
\hline \multirow{3}{*}{\multicolumn{2}{|c|}{ Excluded to align with the screening outreach population }} & Dementia \\
\hline & & End-stage renal disease \\
\hline & & HIV/AIDS \\
\hline \multirow{4}{*}{\multicolumn{2}{|c|}{ Colonoscopy not medically indicated }} & Currently receiving nursing home care \\
\hline & & Currently receiving hospice care \\
\hline & & Currently receiving active treatment for cancer \\
\hline & & Prior colectomy \\
\hline \multirow{3}{*}{\multicolumn{2}{|c|}{ Other exclusions }} & Needs an interpreter to communicate in English \\
\hline & & Opts out of research studies \\
\hline & & No available phone number \\
\hline
\end{tabular}

pre-addressed, stamped envelope to return completed kits. We asked them to return both FIT kits within 7 days of completion of the initial FIT kit, to ensure that sample degradation would be minimal; we did not request that participants refrigerate the samples. When no date was recorded on the kit, we assumed that the kit marked "1" had been completed first and the kit marked "2" had been completed second. FIT kits were stored in a refrigerator for up to 2 weeks until they could be processed using the OC-Auto Micro 80 analyzer (Polymedco, Inc., Cortland Manor, NY).

\section{Reminders}

Participants who did not complete the FIT kits or colonoscopy received up to three reminder calls and a reminder postcard.

\section{Colonoscopy}

Patients who scheduled a colonoscopy within 180 days (6 months) and who completed the colonoscopy within 270 days (9 months) of completing FIT kits were included in the final cohort. Colonoscopies were conducted by 15 experienced staff gastroenterologists, each of whom had performed a minimum of 2000 colonoscopies previously. Gastroenterologists were blinded to the FIT results. One of three gastrointestinal pathologists (also blinded to FIT results) reviewed biopsy results. Participants received a standard bowel preparation including oral intake of $4 \mathrm{~L}$ of polyethylene glycol with electrolyte solution (Gavilyte) or sodium phosphate liquid (Fleet Phosphosoda). Gastroenterologists performed colonoscopies under conscious sedation using intravenous midazolam and fentanyl if desired. 


\section{Histology}

We reviewed colonoscopy results for each participant who completed a colonoscopy within 9 months of completing both FIT kits. Through manual abstraction of both colonoscopy report data and pathology data, we categorized the results of colonoscopy. Lesions were classified as non-neoplastic (e.g., hyperplastic), advanced adenomas, or low-risk adenomas. Advanced adenoma was defined as any adenoma $\geq 10 \mathrm{~mm}$; or with tubular, tubulovillous, or villous histology or high-grade dysplasia (regardless of size); or $\geq 3$ small $(<10 \mathrm{~mm})$ tubular adenomas or serrated lesions [27, 28]. Low-risk (non-advanced) adenoma was defined as 1-2 tubular adenomas or serrated lesions $<10 \mathrm{~mm}$ in diameter, without highgrade dysplasia.

\section{Incidence of colorectal cancer within the screening age- eligible population}

To contextualize the disease rates among individuals within the analytic cohort, we utilized the KPNW Certified Tumor Registry to assess the incidence of CRC among all health plan member adults ages 50-75 during the years 2009 and 2010. We computed incidence rates as cases occurring within 1 month of colonoscopy, using total person-years of observation of health plan members. The tumor registry database systematically captures site, histology, size, staging, and other information on all tumors identified among KPNW members since 1960, as mandated by the Commission on Cancer, Oregon and Washington State reporting guidelines, and agreements with the Center for Health Research. The registry maintains at least annual contact with clinicians and patients, and updates existing cases with survival data.

\section{Number of colonoscopy-detected colorectal cancers among the referral cohort}

To further contextualize disease rates among individuals within the analytic cohort, we evaluated CRC incidence within the referral cohort that served as the initial recruitment source for participants in the study, utilizing electronic procedure codes and the Tumor Registry. Among those within the original referral cohort, but not recruited into the analytic cohort, we identified individuals who had completed a colonoscopy, then received a diagnosis of colorectal cancer within 1 month of completion. We performed chart review to confirm cases and assess whether each patient was of average or high risk for CRC prior to diagnosis.

\section{Analysis}

We considered a positive result for either sample (at the specified cutoff) as an overall positive result within the 2-FIT cohort. We calculated sensitivity, specificity, negative predictive value, and positive predictive value for detection of advanced neoplasia for 1-FIT kit completion and 2-FIT kit completion at a range of hemoglobin concentration cutoffs- $50 \mathrm{ng} / \mathrm{ml}(10 \mu \mathrm{g} / \mathrm{g})$ to $150 \mathrm{ng} / \mathrm{ml}$ $(30 \mu \mathrm{g} / \mathrm{g})$. Differences between the AUCs (Area under the curve) for 1-FIT and 2-FIT generated by prespecified cutoffs were tested using DeLong's test for two correlated ROC curves [29], with the lowest hemoglobin concentration cutoff- $50 \mathrm{ng} / \mathrm{ml}(10 \mu \mathrm{g} / \mathrm{g})$ as the reference group. We also analyzed test performance using chi-square tests for logistic models by gender (male vs. female), by age range (50-64 vs. 65-75), and by a prior FIT having been completed in the health plan. We generated receiver-operating characteristic curves to evaluate effects of these variables on test performance of the 1-FIT kit, using methods as outlined by Gönen [30].

\section{Results}

\section{Recruitment}

Figure 1 shows patient recruitment, eligibility, and participation. We identified 7893 potential participants who had received a referral for screening colonoscopy. Among these, 2761 participants completed both FIT kits and a colonoscopy within 9 months of FIT kit completion. Mean time between dates written on the first and second FIT kits for those who completed both kits was 2 days. An additional 10 participants completed one FIT kit and a colonoscopy within 9 months of FIT kit completion.

\section{Demographics}

Characteristics of the analytic cohort $(N=2771)$, in comparison to those who had received a referral for screening colonoscopy but did not end up in the analytic cohort $(N=5122)$, are shown in Table 2 .

Within the analytic cohort, $48.7 \%$ were male, and 89 . $1 \%$ were White; $3.7 \%$, Asian; $2.2 \%$, Black; $0.5 \%$, Native

Table 2 Comparison of characteristics between analytic cohort and those referred but not in the analytic cohort

\begin{tabular}{|c|c|c|c|c|c|}
\hline & \multicolumn{2}{|c|}{ Analytic Cohort } & \multicolumn{2}{|c|}{ Not in Analytic Cohort } & \multirow[b]{2}{*}{$p$-value } \\
\hline & $\mathrm{N}$ & $\%$ & $\mathrm{~N}$ & $\%$ & \\
\hline \multicolumn{6}{|l|}{ Gender } \\
\hline Female & 1422 & 51.32 & 2689 & 52.5 & \multirow[t]{2}{*}{0.3158} \\
\hline Male & 1349 & 48.68 & 2433 & 47.5 & \\
\hline \multicolumn{6}{|c|}{ Age at Referral } \\
\hline $50-64$ & 2123 & 76.61 & 4086 & 79.77 & \multirow[t]{2}{*}{0.0011} \\
\hline $65-75$ & 648 & 23.39 & 1036 & 20.23 & \\
\hline \multicolumn{6}{|c|}{ Previous FIT in EMR } \\
\hline No & 791 & 28.55 & 2450 & 47.83 & \multirow[t]{2}{*}{$<.0001$} \\
\hline Yes & 1980 & 71.45 & 2672 & 52.17 & \\
\hline All & 2771 & 100 & 5122 & 100 & \\
\hline
\end{tabular}

$p$-value from Chi Square test 


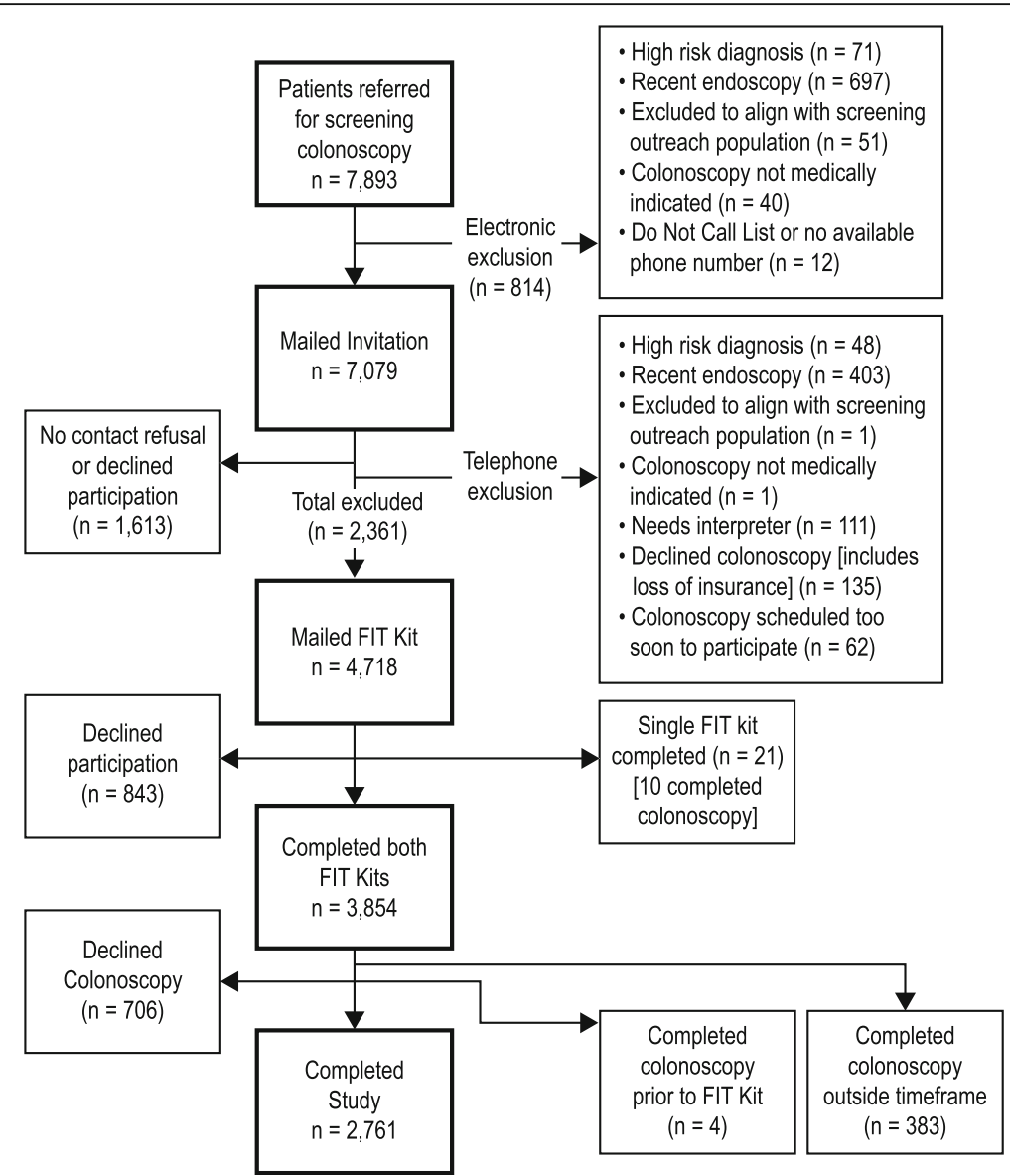

Fig. 1 Study Flow Chart. Note that reasons for exclusion from being mailed an invitation (electronic exclusion) or from being mailed a FIT kit (telephone exclusion) occur at different stages and may overlap. The total ineligible at each step is provided. FIT = Fecal immunochemical test

American; and 2.4\%, multiracial. Race was unknown for 53 participants (1.9\%). Those who reported they were Hispanic totaled $113(4.1 \%)$, and $95.9 \%$ were nonHispanic. Also, 145 (5.2\%) participants reported a family history of CRC in a first-degree relative, and $466(16.8 \%)$ reported a family history of $\mathrm{CRC}$ in any relative.

\section{Colonoscopy results}

Of all participants $(N=2771)$, the cecum was reached in 2688 (97\%). Eighty-three (3\%) of colonoscopies were considered incomplete; 55 (2\%) of participants had insufficient bowel preparation. Table 3 shows colonoscopy findings. Within the analytic cohort, 779 participants (28.1\%) had adenomas (advanced and non-advanced) and 209 (7.5\%) had advanced adenomas. Sixty-two individuals $(2.2 \%)$ had left-sided advanced neoplasia alone, and 150 individuals (5.4\%) had isolated right-sided advanced neoplasia or a combination of right- and leftsided advanced neoplasia. Two participants $(0.07 \%)$ had adenocarcinoma, and one had a carcinoid tumor. Of the two detected adenocarcinomas, one was Duke's Stage A (T1NOM0), and the other was metastatic (T3NOM1b).
FIT sensitivity, specificity, positive predictive value and negative predictive value

Table 4 shows the sensitivity, specificity, negative predictive value, and positive predictive value of both 1 FIT and 2-FIT protocols for detection of advanced neoplasia. Differences in sensitivity and specificity between the 1-FIT and 2-FIT protocols were not

Table 3 Colonoscopy results based on most advanced lesion found

\begin{tabular}{lll}
\hline & Number & Percent \\
\hline No polyps & 1805 & $65.1 \%$ \\
Hyperplastic polyps & 185 & $6.7 \%$ \\
Non-advanced adenoma & 570 & $20.6 \%$ \\
Advanced adenoma & 209 & $7.5 \%$ \\
$3+$ tubular adenomas or serrated lesions $<1 \mathrm{~cm}$ & 92 & $3.3 \%$ \\
Tubular adenomas, serrated lesions $>=1 \mathrm{~cm}$ & 43 & $1.5 \%$ \\
$\quad$ Polyps with high-grade dysplasia & 74 & $2.7 \%$ \\
Colorectal adenocarcinoma & 2 & $0.07 \%$ \\
Advanced neoplasia & 211 & $7.6 \%$ \\
Total & 2771 & $100 \%$ \\
\hline
\end{tabular}


Table 4 Performance of 1-sample and 2-sample FIT for advanced neoplasia at different hemoglobin concentration cutoffs

\begin{tabular}{|c|c|c|c|c|c|c|c|c|c|c|c|c|c|c|}
\hline \multirow[b]{2}{*}{ Test } & \multirow[b]{2}{*}{ Threshold (ng/ml) } & \multirow[t]{2}{*}{$\%$ positive } & \multicolumn{3}{|c|}{ Sensitivity } & \multicolumn{3}{|c|}{ Specificity } & \multicolumn{3}{|l|}{ PPV } & \multicolumn{3}{|l|}{ NPV } \\
\hline & & & Est. & $\mathrm{LL}$ & UL & Est. & LL & UL & Est. & $\mathrm{LL}$ & UL & Est. & LL & UL \\
\hline $1-\mathrm{FIT}$ & 50 & 7.58 & 22.6 & 17.0 & 28.3 & 93.7 & 92.7 & 94.6 & 22.9 & 17.2 & 28.5 & 93.6 & 92.7 & 94.5 \\
\hline $2-\mathrm{FIT}$ & 50 & 11.99 & 29.7 & 23.6 & 35.9 & 89.5 & 88.3 & 90.7 & 19.0 & 14.8 & 23.2 & 93.9 & 92.9 & 94.8 \\
\hline 1-FIT & 75 & 5.09 & 16.5 & 11.5 & 21.5 & 95.9 & 95.1 & 96.6 & 24.8 & 17.7 & 32.0 & 93.3 & 92.3 & 94.2 \\
\hline $2-\mathrm{FIT}$ & 75 & 8.09 & 23.1 & 17.4 & 28.8 & 93.1 & 92.2 & 94.1 & 21.9 & 16.5 & 27.3 & 93.6 & 92.7 & 94.6 \\
\hline 1-FIT & 100 & 4.19 & 14.2 & 9.5 & 18.8 & 96.6 & 95.9 & 97.3 & 25.9 & 17.9 & 33.8 & 93.2 & 92.2 & 94.1 \\
\hline $2-\mathrm{FIT}$ & 100 & 6.50 & 19.3 & 14.0 & 24.7 & 94.6 & 93.7 & 95.5 & 22.8 & 16.7 & 28.9 & 93.4 & 92.4 & 94.4 \\
\hline 1-FIT & 125 & 3.61 & 13.7 & 9.1 & 18.3 & 97.2 & 96.6 & 97.9 & 29.0 & 20.1 & 37.9 & 93.2 & 92.2 & 94.1 \\
\hline $2-\mathrm{FIT}$ & 125 & 5.42 & 18.4 & 13.2 & 23.6 & 95.7 & 94.9 & 96.5 & 26.0 & 19.0 & 33.0 & 93.4 & 92.5 & 94.4 \\
\hline 1-FIT & 150 & 3.03 & 12.3 & 7.9 & 16.7 & 97.7 & 97.2 & 98.3 & 31.0 & 21.1 & 40.8 & 93.1 & 92.1 & 94.0 \\
\hline 2-FIT & 150 & 4.66 & 17.5 & 12.3 & 22.6 & 96.4 & 95.7 & 97.1 & 28.7 & 20.9 & 36.5 & 93.4 & 92.4 & 94.3 \\
\hline
\end{tabular}

statistically significant $(p>.05)$ at any of the prespecified cutoff levels for the FITs. Figure 2 demonstrates that there is no significant difference between ROC curves for 1-FIT and 2-FIT. Table 5 shows comparisons of ROC curves for the 1-sample FIT at each of the hemoglobin concentration cutoffs, with $50 \mathrm{ng} /$ $\mathrm{ml}(10 \mu \mathrm{g} / \mathrm{g})$ as the reference group. There was a significant difference in test performance between $50 \mathrm{ng} / \mathrm{ml}(10 \mu \mathrm{g} / \mathrm{g})$ and every other pre-specified comparison group (i.e., $75 \mathrm{ng} / \mathrm{ml}, 100 \mathrm{ng} / \mathrm{ml}, 125 \mathrm{ng} /$ $\mathrm{ml}$, and $150 \mathrm{ng} / \mathrm{ml})$. Figure 3 demonstrates no difference in test performance of the 1-sample FIT by age group or gender, or by prior FIT completion.
Incidence of colorectal cancer within age-eligible population

Among KPNW members ages 50-75 without a prior diagnosis of $\mathrm{CRC}$, the unadjusted incidence rate of CRC in 2009-2010 was 1.08 per 1000 person-years (95\% CI: 0.99-1.21).

\section{Colonoscopy-detected colorectal cancers within referral cohort}

Of the 7893 individuals with a referral for screening colonoscopy, 5277 (66.9\%) completed the colonoscopy within the study follow-up period. Nine of the 5277 received a diagnosis of colon or rectal cancer within

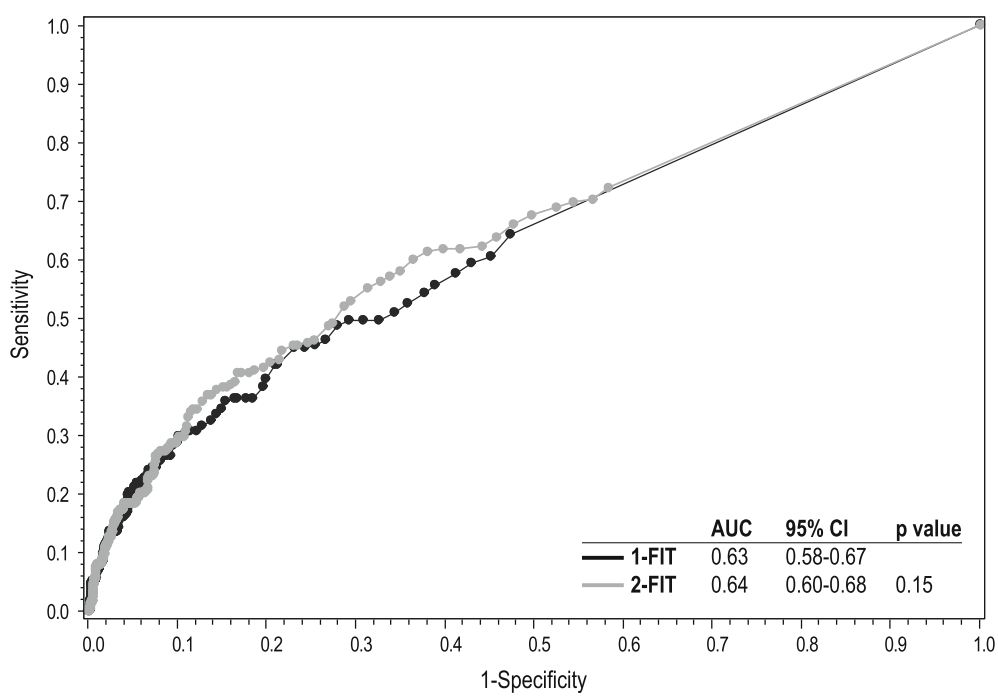

Fig. 2 Receiver operating characteristic curves for advanced neoplasia, comparing 1-sample FIT and 2-sample FIT; demonstrates that there is no significant difference between ROC curves for 1-FIT and 2-FIT. Each line represents the highest fecal immunochemical hemoglobin measurement from the specified number of fecal samples collected and the corresponding maximum sensitivity and specificity at a given hemoglobin concentration cutoff, from $50 \mathrm{ng} / \mathrm{ml}(10 \mu \mathrm{g} / \mathrm{g})$ to $150 \mathrm{ng} / \mathrm{ml}(30 \mathrm{\mu g} / \mathrm{g})$. FIT-1 = first fecal immunochemical test sample collected; FIT-2 = both fecal immunochemical test samples collected; $A \cup C$ = area under the curve 
Table 5 Test of differences between the Area Under the Curve (AUC) for pre-specified hemoglobin concentration cutoffs

\begin{tabular}{lllll}
\hline & Reference group & Comparator group & Z - stats & $p$-value \\
\hline Threshold $(\mathrm{ng} / \mathrm{ml})$ & 50 & 75 & 2.3587 & 0.01834 \\
AUC & 0.58209 & 0.56223 & 2.8421 & 0.00448 \\
Threshold $(\mathrm{ng} / \mathrm{ml})$ & 50 & 100 & 2.7122 \\
AUC & 0.58209 & 0.55429 & 0.00668 \\
Threshold $(\mathrm{ng} / \mathrm{ml})$ & 50 & 125 & 2.9666 \\
AUC & 0.58209 & 0.55485 & 0.00301 \\
Threshold $(\mathrm{ng} / \mathrm{ml})$ & 50 & 150 & 0.55028 & \\
AUC & 0.58209 & &
\end{tabular}

$p$-value from DeLong's test for two correlated ROC curves

1 month of the colonoscopy (0.2\%); of these, six were of average risk for CRC (two were in the analytic cohort; two had agreed to participate but did not follow through with FIT kit completion, two had declined participation), and three were not in the study because of high-risk features (i.e., suggestive bowel symptoms, inherited colorectal cancer syndrome).

\section{Discussion}

Testing two fecal samples rather than one did not significantly improve FIT performance in detecting advanced neoplasia, at any pre-specified cutoff of hemoglobin concentration, among a younger, previously screened population in which advanced neoplasia incidence was low. Test performance did not vary by age category, gender, or prior FIT completion, indicating that targeting these subgroups would not significantly improve detection of advanced neoplasia within similar populations. A major limitation of this study was the low number of invasive cancers (2 out of 2,771), meaning that the findings pertain more specifically to test performance in detection of advanced adenomas.
Two prior studies of this FIT, with colonoscopy as the reference standard (one in a small, asymptomatic population and one in high-risk or symptomatic patients) had similar findings to those of this study; there was no significant difference in test performance between one, two, and three samples for detection of advanced neoplasia [31, 32]. An additional prior study of asymptomatic patients found that testing two samples with the OC-Micro FIT was more sensitive in detecting CRC than one sample [31]. This study was smaller, had a relatively high incidence of colorectal cancers [33], and drew its population mainly from specialty centers. Recent cohort studies comparing yield of CRC and advanced neoplasia between populations screening with 1-sample and 2-sample iterations (at the same hemoglobin concentration cutoff) of the same FIT used in this study found no significant difference in disease yield between groups [34], even after 2 rounds of screening [35]. Another cohort study found that the 2-sample iteration of this FIT yielded more cases with CRC and advanced neoplasia, but that comparable yield could be attained by lowering the
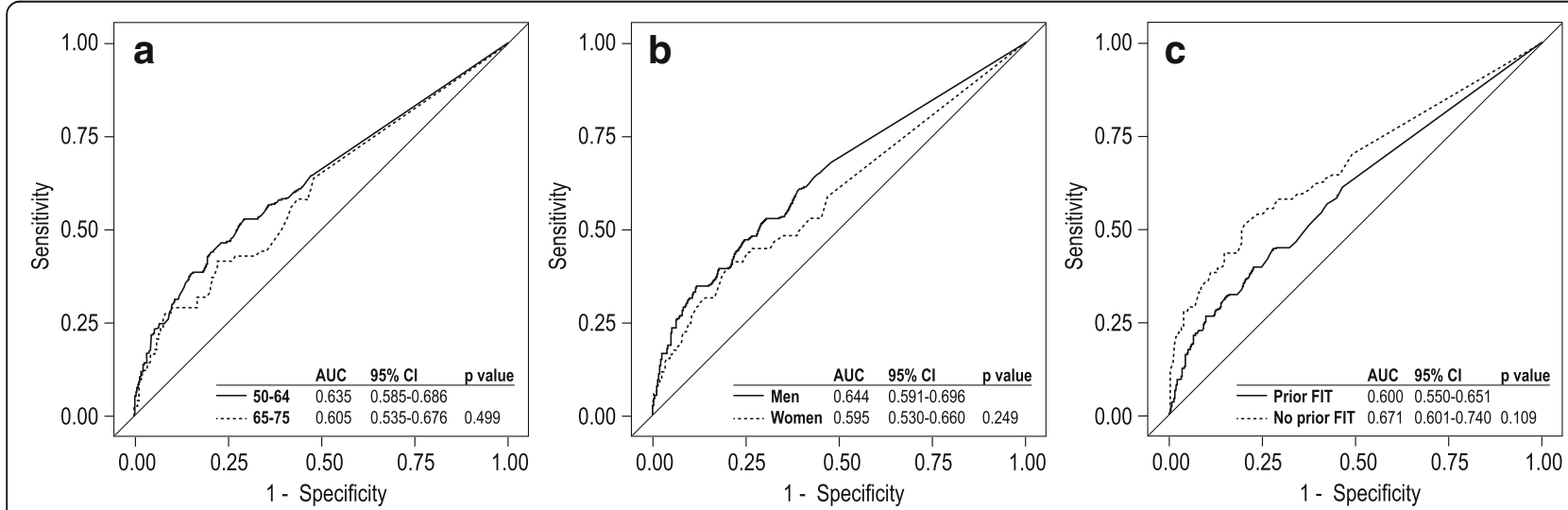

Fig. 3 Receiver operating characteristic curves for advanced neoplasia with a 1-sample FIT, comparing different subgroups; demonstrates no difference in test performance of the 1-sample FIT by age group or gender, or by prior FIT completion. The figure shows ROC curves for a range of hemoglobin concentration cutoffs, from $50 \mathrm{ng} / \mathrm{ml}(10 \mu \mathrm{g} / \mathrm{g})$ to $150 \mathrm{ng} / \mathrm{ml}$ (30 $\mu \mathrm{g} / \mathrm{g})$. a Comparing adults ages $50-64$ to those ages 65-75. b Comparing men and women. c Comparing those who have completed a FIT to those who have not previously completed a FIT. FIT = Fecal immunochemical test; $A U C=$ area under the curve 
hemoglobin concentration cutoff for the single-sample iteration of FIT [36].

There was an increase in sensitivity with a decrease in hemoglobin concentration cutoff, with significant differences in test performance when comparing $50 \mathrm{ng} / \mathrm{ml}$ $(10 \mu \mathrm{g} / \mathrm{g})$ to every successive higher preset hemoglobin concentration we studied (including the manufacturer recommended cutoff of $100 \mathrm{ng} / \mathrm{ml}[20 \mu \mathrm{g} / \mathrm{g}]$ ). These findings confirmed trends noted in other similarly designed studies of the OC Auto FIT [31, 37, 38]. The optimal cutoff for a screening program will vary based on local resources. While lowering the hemoglobin concentration cutoff for FIT will make the test more sensitive for advanced neoplasia (in particular, proximal lesions) [39], there is a tradeoff in higher overall positivity rates and higher false positive rates [38]. Previously studied asymptomatic populations screened with the single-sample OC Auto FIT at the lower hemoglobin concentration cutoff of $50 \mathrm{ng} / \mathrm{ml}(10 \mu \mathrm{g} / \mathrm{g})$ have had positive FIT results in $8-14 \%$ of participants on the first screening round [31, 35], although the proportion with a positive test result at this cutoff in our study was $7.6 \%$. Maintenance of access to diagnostic colonoscopy for those with a positive FIT result remains an important consideration in implementing an organized CRC screening program based on mailed FIT kits [40-42], especially if the program also needs to maintain access to primary screening colonoscopy as an available option [43].

Notable strengths of our study include the prospective design, relatively large sample size, and thorough exclusion of high-risk individuals (including those with a prior history of adenomas and those with symptoms suggestive of colorectal cancer). This is the largest prospective cohort study evaluating test performance of different iterations of this quantitative FIT, and colonoscopy served as the reference standard for all participants. The study occurred in a real-world integrated care setting, where participants had access to CRC screening (and the majority had previously completed screening). Our study also had limitations. The number of participants with advanced neoplasms was low, and so we do not address the question of whether testing of two samples would detect more colorectal cancers; we did not have enough cancer cases to assess this endpoint. Our one-time sensitivity estimates for advanced neoplasia are lower than those in prior studies with a higher incidence of colorectal neoplasms, due to spectrum effect [33, 44-46]; this makes estimation of 'true' sensitivity for this FIT challenging. Lastly, because of fluctuation in and varying durations of health plan membership, we were unable to accurately assess the proportion of patients who had had a prior negative endoscopy (e.g., a colonoscopy greater than
10 years prior or a flexible sigmoidoscopy greater than 5 years prior to enrollment).

\section{Conclusions}

Our study findings confirm that a FIT outreach program within the United States, where overall screening rates in the country approximate 60\% [47], would most efficiently utilize a single-sample FIT. Decreasing the hemoglobin concentration cutoff from the manufacturerrecommended cutoff of $100 \mathrm{ng} / \mathrm{ml}(20 \mu \mathrm{g} / \mathrm{g})$ to $50 \mathrm{ng} / \mathrm{ml}$ $(10 \mu \mathrm{g} / \mathrm{g})$ significantly increased sensitivity of the singlesample FIT for advanced neoplasia. Further research should continue to study initiation of organized screening programs to replace opportunistic screening, especially within health systems in which screening is a covered benefit [48]. Further research should also optimize the reach [49] of organized screening programs across different settings that have variable access to diagnostic colonoscopy [50].

\section{Abbreviations}

AUC: Area under the curve; CRC: Colorectal cancer; EMR: Electronic medical record; FIT: Fecal immunochemical test; HMO: Health maintenance organization; KPNW: Kaiser Permanente Northwest; ROC: Receiver-operating characteristic curves; USPSTF: United States Preventive Services Task Force

\section{Acknowledgements}

The authors thank Lucy Fulton for project and clinic personnel management; Matthew Hornbrook for database programming and management; Erin Keast for data analysis; Azonia Haney and Donna White for patient recruitment; Kim Olson and Jill Mesa for chart abstraction; Jill Pope for editing; Lisa Fox for graphics; Helen Landicho for correspondence with Polymedco; and Robin Daily and Elizabeth Boling for manuscript formatting.

\section{Funding}

Funding for this study was provided by the National Institutes of Health, Grant \#R01CA154982-04, from the National Cancer Institute. Neither NIH nor $\mathrm{NCl}$ had a role in study design or in collection, analysis or interpretation of data, or in writing of the report. Polymedco, Inc. (Cortland Manor, NY), supplied OC-Auto FIT kits and an OC-Auto Micro analyzer; it had no role in study design or in collection, analysis or interpretation of data, or in writing of the report.

\section{Availability of data and materials}

The datasets generated and/or analyzed during the current study are available from the corresponding author on reasonable request.

\section{Authors' contributions}

EGL — study design, data collection, data analysis, interpretation of data, writing of report. NP_-study design, data analysis, interpretation of data, writing of report. AGR - data collection, data analysis, interpretation of data. DHS - data analysis, interpretation of data, writing of report. ACF_-study design, interpretation of data, writing of report. DM—data collection, interpretation of data. TRL - interpretation of data, writing of report. All authors approved the final draft submitted.

\section{Ethics approval and consent to participate}

The Kaiser Permanente Northwest Institutional Review Board approved the study on August 23, 2011. Participants who gave verbal consent to be part of the study received an information sheet in the mail (with the 2 FIT kits enclosed) explaining the benefits, risks and costs of the study and outlining other elements of informed consent. Given that there were no study visits, the Institutional Review Board approved verbal consent with distribution of the information sheet, to enable feasibility of study completion. 


\section{Competing interests}

The authors declare that they have no competing interests.

\section{Publisher's Note}

Springer Nature remains neutral with regard to jurisdictional claims in published maps and institutional affiliations.

\section{Author details}

'Kaiser Permanente Center for Health Research, 3800 N Interstate Ave, Portland, OR 97227, USA. Johns Hopkins School of Nursing, 525 N Wolfe St, Baltimore, MD 21205, USA. ${ }^{3}$ Kaiser Permanente Medical Center, 1425 S. Main Street, Walnut Creek, CA 94596, USA.

\section{Received: 20 July 2017 Accepted: 18 April 2018}

Published online: 02 May 2018

\section{References}

1. American Cancer Society. Cancer Facts \& Figures 2018. https://www.cancer. org/research/cancer-facts-statistics/all-cancer-facts-figures/cancer-factsfigures-2018.html. Accessed 29 Apr 2018.

2. Hewitson P, Glasziou P, Irwig L, Towler B, Watson E. Screening for colorectal cancer using the faecal occult blood test, Hemoccult. Cochrane Database Syst Rev. 2007;(1):CD001216.

3. Winawer SJ, Zauber AG, Ho MN, O'Brien MJ, Gottlieb LS, Sternberg SS, Waye JD, Schapiro M, Bond JH, Panish JF, et al. Prevention of colorectal cancer by colonoscopic polypectomy. The National Polyp Study Workgroup. N Engl J Med. 1993;329(27):1977-81.

4. Atkin WS, Edwards R, Kralj-Hans I, Wooldrage K, Hart AR, Northover JM, Parkin DM, Wardle J, Duffy SW, Cuzick J. Once-only flexible sigmoidoscopy screening in prevention of colorectal cancer: a multicentre randomised controlled trial. Lancet. 2010:375(9726):1624-33.

5. Holme O, Loberg M, Kalager M, Bretthauer M, Hernan MA, Aas E, Eide TJ, Skovlund E, Schneede J, Tveit KM, et al. Effect of flexible sigmoidoscopy screening on colorectal cancer incidence and mortality: a randomized clinical trial. JAMA. 2014;312(6):606-15.

6. Segnan N, Armaroli P, Bonelli L, Risio M, Sciallero S, Zappa M, Andreoni B, Arrigoni A, Bisanti L, Casella C, et al. Once-only sigmoidoscopy in colorectal cancer screening: follow-up findings of the Italian randomized controlled trial-SCORE. J Natl Cancer Inst. 2011:103(17):1310-22.

7. van Rossum LG, van Rijn AF, Laheij RJ, van Oijen MG, Fockens P, van Krieken $\mathrm{HH}$, Verbeek $\mathrm{AL}$, Jansen JB, Dekker E. Random comparison of guaiac and immunochemical fecal occult blood tests for colorectal cancer in a screening population. Gastroenterology. 2008;135(1):82-90.

8. Hoffman RM, Steel SR, Yee EF, Massie L, Schrader RM, Murata GH. Colorectal cancer screening adherence is higher with fecal immunochemical tests than guaiac-based fecal occult blood tests: a randomized, controlled trial. Prev Med. 2010;50(5-6):297-9.

9. Federici A, Giorgi RP, Borgia P, Bartolozzi F, Farchi S, Gausticchi G. The immunochemical faecal occult blood test leads to higher compliance than the guaiac for colorectal cancer screening programmes: a cluster randomized controlled trial. J Med Screen. 2005;12(2):83-8.

10. Hol L, Wilschut JA, van Ballegooijen M, van Vuuren AJ, van der Valk $H$, Reijerink JC, van der Togt AC, Kuipers EJ, Habbema JD, van Leerdam ME. Screening for colorectal cancer: random comparison of guaiac and immunochemical faecal occult blood testing at different cut-off levels. $\mathrm{Br}$ Cancer. 2009;100(7):1103-10.

11. Rabeneck L, Rumble RB, Thompson F, Mills M, Oleschuk C, Whibley A, Messersmith $\mathrm{H}$, Lewis $\mathrm{N}$. Fecal immunochemical tests compared with guaiac fecal occult blood tests for population-based colorectal cancer screening. Can J Gastroenterol. 2012;26(3):131-47.

12. Robertson DJ, Lee JK, Boland CR, Dominitz JA, Giardiello FM, Johnson DA Kaltenbach T, Lieberman D, Levin TR, Rex DK. Recommendations on fecal immunochemical testing to screen for colorectal neoplasia: a consensus statement by the US multi-society task force on colorectal cancer. Gastroenterology. 2017;152(5):1217-37. e1213

13. US Preventive Services Task Force: Screening for colorectal cancer. US preventive services task force recommendation statement. JAMA. 2016; 315(23):2564-75.

14. Wilt TJ, Harris RP, Qaseem A. Screening for cancer: advice for high-value care from the American College of Physicians. Ann Intern Med. 2015; 162(10):718-25.
15. Lee JK, Liles EG, Bent S, Levin TR, Corley DA. Accuracy of fecal immunochemical tests for colorectal cancer: systematic review and metaanalysis. Ann Intern Med. 2014;160(3):171.

16. Allison JE. FIT: a valuable but underutilized screening test for colorectal cancer-it's time for a change. Am J Gastroenterol. 2010; 105(9):2026-8

17. Navarro M, Nicolas A, Ferrandez A, Lanas A. Colorectal cancer population screening programs worldwide in 2016: an update. World J Gastroenterol. 2017;23(20):3632-42.

18. US National Institutes of Health. Colonoscopy Versus Fecal Immunochemical Test in Reducing Mortality From Colorectal Cancer. https://clinicaltrials.gov/ ct2/show/study/NCT01239082. Accessed Sept 62016.

19. Quintero E, Castells A, Bujanda L, Cubiella J, Salas D, Lanas A, Andreu M, Carballo F, Morillas JD, Hernandez C, et al. Colonoscopy versus fecal immunochemical testing in colorectal-cancer screening. N Engl J Med. 2012;366(8):697-706

20. Jensen CD, Corley DA, Quinn VP, Doubeni CA, Zauber AG, Lee JK, Zhao WK Marks AR, Schottinger JE, Ghai NR, et al. Fecal immunochemical test program performance over 4 rounds of annual screening: a retrospective cohort study. Ann Intern Med. 2016;164(7):456-63.

21. Fraser CG, Allison JE, Halloran SP, Young GP. A proposal to standardize reporting units for fecal immunochemical tests for hemoglobin. J Natl Cancer Inst. 2012;104(11):810-4.

22. Mosen DM, Liles EG, Feldstein AC, Perrin N, Rosales AG, Keast E, Smith DH. Participant uptake of the fecal immunochemical test decreases with the two-sample regimen compared with one-sample FIT. Eur J Cancer Prev. 2014;23(6):516-23.

23. National Institute for Health and Clinical Excellence. Suspected cancer, recognition and referral. 1.3 Lower gastrointestinal tract cancers [Internet]. [Updated 2015 June 23]. https://www.nice.org.uk/guidance/NG12/chapter/1 Recommendations-organised-by-site-of-cancer\#lower-gastrointestinal-tractcancers. Accessed Sept 62016.

24. Adelstein BA, Macaskill P, Chan SF, Katelaris PH, Irwig L. Most bowel cancer symptoms do not indicate colorectal cancer and polyps: a systematic review. BMC Gastroenterol. 2011;11:65.

25. Jellema P, van der Windt DA, Bruinvels DJ, Mallen CD, van Weyenberg J, Mulder CJ, de Vet HC. Value of symptoms and additional diagnostic tests for colorectal cancer in primary care: systematic review and meta-analysis. BMJ. 2010;340:c1269.

26. Ford AC, Veldhuyzen van Zanten SJ, Rodgers CC, Talley NJ, Vakil NB, Moayyedi P. Diagnostic utility of alarm features for colorectal cancer: systematic review and meta-analysis. Gut. 2008;57(11):1545-53.

27. van Heijningen EM, Lansdorp-Vogelaar I, Kuipers EJ, Dekker E, Lesterhuis W, Ter Borg F, Vecht J, De Jonge $V$, Spoelstra $P$, Engels $L$, et al. Features of adenoma and colonoscopy associated with recurrent colorectal neoplasia based on a large community-based study. Gastroenterology. 2013;144(7):1410-8.

28. Lieberman DA, Rex DK, Winawer SJ, Giardiello FM, Johnson DA, Levin TR. Guidelines for colonoscopy surveillance after screening and polypectomy: a consensus update by the US multi-society task force on colorectal cancer. Gastroenterology. 2012:143(3):844-57.

29. DeLong ER, DeLong DM, Clarke-Pearson DL. Comparing the areas under two or more correlated receiver operating characteristic curves: a nonparametric approach. Biometrics. 1988;44(3):837-45.

30. Gönen M. Analyzing receiver operating characteristic curves with SAS. Cary, NC: SAS Institute Inc:; 2007

31. Park DI, Ryu S, Kim YH, Lee SH, Lee CK, Eun CS, Han DS. Comparison of guaiac-based and quantitative immunochemical fecal occult blood testing in a population at average risk undergoing colorectal cancer screening. Am I Gastroenterol. 2010;105(9):2017-25.

32. Rozen P, Levi Z, Hazazi R, Waked A, Vilkin A, Maoz E, Birkenfeld S, Leshno M, Niv Y. Identification of colorectal adenomas by a quantitative immunochemical faecal occult blood screening test depends on adenoma characteristics, development threshold used and number of tests performed. Aliment Pharmacol Ther. 2009;29(8):906-17.

33. Heitman SJ, Ronksley PE, Hilsden RJ, Manns BJ, Rostom A, Hemmelgarn $B R$. Prevalence of adenomas and colorectal cancer in average risk individuals: a systematic review and meta-analysis. Clin Gastroentero Hepatol. 2009;7(12):1272-8.

34. Faivre J, Dancourt V, Manfredi S, Denis B, Durand G, Gendre I, Bidan JM, Jard $C$, Levillain $R$, Jung $S$, et al. Positivity rates and performances of 
immunochemical faecal occult blood tests at different cut-off levels within a colorectal cancer screening programme. Dig Liver Dis. 2012;44(8):700-4.

35. Kapidzic $A$, van Roon AH, van Leerdam ME, van Vuuren AJ, van Ballegooijen M, Lansdorp-Vogelaar I, Spijker W, Izelaar K, Hol L, Kuipers EJ. Attendance and diagnostic yield of repeated two-sample faecal immunochemical test screening for colorectal cancer. Gut. 2017;66(1):118-23.

36. Raginel T, Puvinel J, Ferrand O, Bouvier V, Levillain R, Ruiz A, Lantieri O, Launoy G, Guittet L. A population-based comparison of immunochemical fecal occult blood tests for colorectal cancer screening. Gastroenterology. 2013;144(5):918-25.

37. de Wijkerslooth TR, Stoop EM, Bossuyt PM, Meijer GA, van Ballegooijen $M$, van Roon AH, Stegeman I, Kraaijenhagen RA, Fockens P, van Leerdam ME, et al. Immunochemical fecal occult blood testing is equally sensitive for proximal and distal advanced neoplasia. Am J Gastroenterol. 2012:107(10):1570-8.

38. Aniwan S, Ratanachu Ek T, Pongprasobchai S, Limsrivilai J, Praisontarangkul OA, Pisespongsa P, Mairiang P, Sangchan A, Sottisuporn J, Wisedopas N, et al. The optimal cut-off level of the fecal immunochemical test for colorectal cancer screening in a country with limited colonoscopy resources: a multicenter study from Thailand. Asian Pac J Cancer Prev. 2017;18(2):405-12.

39. Cha JM, Lee JI, Joo KR, Shin HP, Jeun JW, Lim JU. Use of a low cut-off value for the fecal immunochemical test enables better detection of proximal neoplasia. Dig Dis Sci. 2013;58(11):3256-62.

40. Subramanian S, Bobashev G, Morris RJ. When budgets are tight, there are better options than colonoscopies for colorectal cancer screening. Health Aff (Millwood). 2010;29(9):1734-40.

41. Joseph DA, Meester RG, Zauber AG, Manninen DL, Winges L, Dong FB, Peaker B, van Ballegooijen M. Colorectal cancer screening: estimated future colonoscopy need and current volume and capacity. Cancer. 2016;122(16):2479-86.

42. Oluloro A, Petrik AF, Turner A, Kapka T, Rivelli J, Carney PA, Saha S, Coronado GD. Timeliness of colonoscopy after abnormal fecal test results in a safety net practice. J Community Health. 2016;41(4):864-70.

43. Liles EG, Schneider JL, Feldstein AC, Mosen DM, Perrin N, Rosales AG, Smith $\mathrm{DH}$. Implementation challenges and successes of a population-based colorectal cancer screening program: a qualitative study of stakeholder perspectives. Implement Sci. 2015:10:41.

44. Rutjes AW, Reitsma JB, Di Nisio M, Smidt N, van Rijn JC, Bossuyt PM. Evidence of bias and variation in diagnostic accuracy studies. CMAJ. 2006; 174(4):469-76

45. Brenner $\mathrm{H}$, Gefeller O. Variation of sensitivity, specificity, likelihood ratios and predictive values with disease prevalence. Stat Med. 1997;16(9):981-91.

46. Mulherin SA, Miller WC. Spectrum bias or spectrum effect? Subgroup variation in diagnostic test evaluation. Ann Intern Med. 2002;137(7):598-602.

47. Shapiro JA, Klabunde CN, Thompson TD, Nadel MR, Seeff LC, White A. Patterns of colorectal cancer test use, including $C T$ colonography, in the 2010 National Health Interview Survey. Cancer Epidemiol Biomark Prev. 2012;21(6):895-904.

48. Hatch QM, Kniery KR, Johnson EK, Flores SA, Moeil DL, Thompson JJ, Maykel $J$ A, Steele SR. Screening or symptoms? How do we detect colorectal cancer in an equal access health care system? J Gastrointest Surg. 2016;20(2):431-8.

49. Glasgow RE, Vogt TM, Boles SM. Evaluating the public health impact of health promotion interventions: the RE-AIM framework. Am J Public Health. 1999;89(9):1322-7.

50. Coronado GD, Schneider UL, Petrik A, Rivelli J, Taplin S, Green BB. Implementation successes and challenges in participating in a pragmatic study to improve colon cancer screening: perspectives of health center leaders. Transl Behav Med. 2017;7(3):557-66.

\section{Ready to submit your research? Choose BMC and benefit from:}

- fast, convenient online submission

- thorough peer review by experienced researchers in your field

- rapid publication on acceptance

- support for research data, including large and complex data types

- gold Open Access which fosters wider collaboration and increased citations

- maximum visibility for your research: over $100 \mathrm{M}$ website views per year

At BMC, research is always in progress.

Learn more biomedcentral.com/submissions 